Изв. АН Эстонии, Геол., 1989, 38, № 3, 124-127

УДК $622.271 .14 ; 550.8$

P. ПЯЗОК, К. ТЕННО

\title{
О КОНДИЦИОННОСТИ ФОСФОРИТОВ МЕСТОРОЖДЕНИЯ ТООЛСЕ
}

Прибалтийские ракушечные фосфориты относятся к категории бедного сырья. Их переработка в фосфорсодержащие минеральные удобрения невозможна без предварительного флотационного или еще более сложного обогащения. $\mathrm{K}$ полученному при обогащении концентрату предъявляются очень жесткие требования в части содержания полезного компонента и вредных примесей - соединений окислов магния и железа (ТУ-113-12-96-82).

Технические условия на концентрат диктуют соответствующие требования к исходному обогащаемому сырью. Последние должны гарантировать возможность получения из него концентрата нужного качества. На основе кондиций на сырье производится оконтуривание месторождений и подсчет их промышленных запасов.

Месторождение Тоолсе предполагалось эксплуатировать открытым способом. Кондиции на его сырье были разработаны в 1971 г. ВНИИ галургии и включали следующие показатели по содержанию компонентов в массиве: минимальное содержание $\mathrm{P}_{2} \mathrm{O}_{5}$ в пробе (бортовое содержание) $4 \%$; минимальное среднее содержание $\mathrm{P}_{2} \mathrm{O}_{5}$ по подсчетному блоку (промминимум) 8,5\%; максимальное среднее содержание $\mathrm{MgO}$ по подсчетному блоку $0,6 \%$; максимальное отношение $\mathrm{Fe}_{2} \mathrm{O}_{3} / \mathrm{P}_{2} \mathrm{O}_{5}$ (железистый модуль) 0,19. На основе этих кондиций были определены промышленные запасы месторождения 263 млн. т руды при средних содержаниях $\mathrm{P}_{2} \mathrm{O}_{5}-10,36 \%, \mathrm{MgO}-0,49 \%$ и $\mathrm{Fe}_{2} \mathrm{O}_{3}-1,59 \%$ (модуль 0,15 ). Запасы были оценены как пригодные для переработки в качественный концентрат и приняты на государственный баланс. Сырье характеризовалось в целом как низкомагнезиальное, но местами имеющее повышенное содержание $\mathrm{Fe}_{2} \mathrm{O}_{3}$.

Разработанные кондиции представлены некоторыми усредненными показателями, распространяющимися на весьма крупные части месторождения - подсчетные блоки. Средняя величина запасов одного блока составляет около 26 млн. т руды, что превышает объем 4-летней добычи предприятия по проекту. Внутри каждого блока возможны большие колебания показателей качества сырья, что чрезвычайно затрудняет обеспечение обогатительной фабрики сырьем стабильного состава. Кондиционным же требованиям должен в первую очередь отвечать поток поступающего с горнодобывающего предприятия сырья, а не запасы какого-то блока или месторождения в целом. Кстати, это требование оговорено в пункте 2.6 действующей инструкции по кондициям (Инструкция ..., 1983).

Для оценки кондиционности сырья с учетом изменчивости его качества по площади месторождения нами были выполнены статистические исследования сети разведочных скважин по данным химических анализов керновых проб. В каждой скважине мощность промпласта определялась по минимальному содержанию $\mathrm{P}_{2} \mathrm{O}_{5}$ в пробе $4 \%$ (бортовое содержание). В пределах этой мощности определялись средние значения $\mathrm{P}_{2} \mathrm{O}_{5}$, $\mathrm{MgO}, \mathrm{Fe}_{2} \mathrm{O}_{3}$ и $\mathrm{Fe}_{2} \mathrm{O}_{3} / \mathrm{P}_{2} \mathrm{O}_{5}$. Единую статистическую совокупность составляли 399 буровых скважин в контурах промышленных запасов месторождения. Қаждая из них характеризовалась своими показателями 
Статистические показатели качества сырья в контурах промышленных запасов месторождения

\begin{tabular}{l|c|c|c|c|c}
\hline $\begin{array}{c}\text { Нанменование } \\
\text { параметра }\end{array}$ & $\begin{array}{c}\text { Закон } \\
\text { распределения }\end{array}$ & $\begin{array}{c}\text { Вариационный } \\
\text { размах }\end{array}$ & $\begin{array}{c}\text { Среднее } \\
\text { значение }\end{array}$ & $\begin{array}{c}\text { Стандарт- } \\
\text { ное от- } \\
\text { клонение }\end{array}$ & $\begin{array}{c}\text { Уровень } \\
\text { кондицин- } \\
\text { ности }\end{array}$ \\
\hline $\mathrm{P}_{2} \mathrm{O}_{5}, \%$ & норм. & $4,1-19,5$ & 10,9 & 2,47 & 0,83 \\
$\mathrm{MgO}_{0}, \%$ & лог.-норм. & $0,07-3,9$ & 0,54 & 0,4 & 0,68 \\
$\mathrm{Fe}_{2} \mathrm{O}_{3} / \mathrm{P}_{2} \mathrm{O}_{5}$ & лог.-норм. & $0,05-0,92$ & 0,16 & 0,072 & 0,75 \\
$\begin{array}{l}\mathrm{Coвокупность} \\
\text { параметров }\end{array}$ & - & - & - & - & 0,48
\end{tabular}

содержания компонентов и представляла определенную часть этих запасов. В среднем на одну скважину приходилось около 660 тыс. т руды.

В обработке данных участвовали А. Маамяги и С. Малыгин. Был использован пакет программ Института кибернетики АН ЭССР по статистическому анализу, применялся также персональный компьютер KAУPRO (типа IBM РС). Результаты исследований приведены в таблице.

Средние значения содержаний компонентов в сырье и их молулей близки к данным, полученным геологами при подсчете запасов месторождения. Содержание $\mathrm{P}_{2} \mathrm{O}_{5}$ является довольно стабильным, содержания же вредных примесей колеблются в широких пределах. Наибольшая колеблемость характерна для $\mathrm{MgO}$.

Неожиданностью оказалась наименьшая кондиционность сырья по содержанию окиси магния (таблица). До сих пор считалось, что проблема магнезиальности на месторождении Тоолсе не может возникнуть. По совокупности всех трех параметров уровень кондиционности сырья составляет $48 \%$, значит, примерно половина утвержденных балансовых запасов месторождения являются некондиционным сырьем.

Кондиционность определяется не только технологическими возможностями, но и экономической целесообразностью использования сырья, что должно отражаться на величине устанавливаемого промминимума $\mathrm{P}_{2} \mathrm{O}_{5}$ в блоке. Этот параметр требует корректировки в соответствии с имеющимися на сегодняшний день экономическими показателями и оценками. В материалах Госгорхимпроекта по месторождению Тоолсе себестоимость тонны $\mathrm{P}_{2} \mathrm{O}_{5}$ в концентрате определена 138 руб., или на тонну исходного сырья (при товарном выходе продукта 0,066) 9,1 руб. Действующая оптовая цена на прибалтийский фосконцентрат составляет в расчете на тонну $\mathrm{P}_{2} \mathrm{O}_{5} 153$ руб.

Подставив эти величины в известное аналитическое выражение промминимума, получим

$$
\alpha_{\min }=\frac{100 C_{\mathrm{p}} \cdot a}{Ц \cdot K_{\text {обог }}\left(1-K_{\text {pas }}\right)}=\frac{100 \cdot 9,1 \cdot 1,1}{153 \cdot 0,692(1-0,06)}=10 \%,
$$

где $C_{\mathrm{p}}=9,1$ руб. - затраты на добычу и обогащение тонны руды; $a=1,1$ - коэффициент роста затрат; $Ц=153$ руб. - действующая оптовая цена концентрата (за тонну $\mathrm{P}_{2} \mathrm{O}_{5}$ ); $K_{\text {обог }}=0,692$ - извлечение $\mathrm{P}_{2} \mathrm{O}_{5}$ из сырой руды при обогащении; $K_{\text {раз }}=0,06-$ коэффициент разубоживания.

Таким образом промминимум $8,5 \% \quad \mathrm{P}_{2} \mathrm{O}_{5}$ не обеспечивает рентабельной отработки блока. Пересчет на требуемые $10 \%$ приведет к существенному уменьшению извлекаемых запасов. По совокупности рассматриваемых параметров уровень кондиционности запасов месторождения уменьшается до $39 \%$.

Эксплуатация месторождения представляет в таких условиях чрезвычайно сложную задачу. 
По проекту месторождение намечалось эксплуатировать бестранспортной системой открытых горных работ с экскаваторной перевалкой вскрышных пород во внутренний отвал. Эта система характеризуется высоким уровнем концентрации горных работ и минимальным количеством занятой вскрышной и добычной техники. В одновременной работе по проекту находятся всего три добычных забоя, перемещение которых подчинено общему ритму и принятому направлению подвигания фронта горных работ. Поэтому возможности управления качеством сырья в общекарьерном рудопотоке путем перераспределения объемов добычи между экскаваторами здесь ограничены.

Эмпирические зависимости теории усреднения (Бастан и др., 1979) показывают, что при отсутствии регулирования частных потоков предельный коэффициент усреднения в таком случае составляет

$$
\eta_{\max }=1-\frac{1}{\sqrt{3}}=0,42 .
$$

В некоторой степени стабилизировать качество сырья можно путем создания буферных усреднительных складов между карьером и обогатительной фабрикой. Это сложные и дорогие сооружения, стоимость которых пропорциональна их емкости. К тому же, как показывают расчеты по формулам упомянутой теории усреднения, в условиях карьера Тоолсе они способны повысить коэффициент усреднения всего на $25 \%$.

Возможных способов усреднения может оказаться недостаточно для обеспечения обогатительной фабрики сырьем требуемого качества. В таком случае придется оставлять в целиках участки некондиционных запасов при эксплуатации месторождения, как это делается сейчас на Кингисеппском карьере (Загураев, Ларичкин, 1979). При сравнительно большой глубине горных работ в центральной и южной частях месторождения Тоолсе это весьма непростое дело, учитывая ограниченность резерва линейных параметров драглайнов.

Объективная оценка кондиционности сырья месторождения Тоолсе должна быть логично завершена. Необходим пересчет принятых на баланс запасов с учетом реальных возможностей получения из него сырья требуемого качества и отбраковкой некондиционных участков. В противном случае сырье будет пригодно лишь для использования в качестве фосфоритной муки - практически бесполезного по своим агрохимическим свойствам минерального удобрения.

\section{ЛИТЕРАТ У РА}

Бастан П. П., Азбель Е. И., Ключкин Е. И. Теория и практика усреднения руд. М., 1979.

- Загураев В. Г., Ларичкин Ф. Д. Эффективность выявлення и оконтуривания срединных песчаников при отработке Кингисеппского месторождения // Промышленность горнохимического сырья. Вып. 6. М., 1979, 4-6.

Инструкция о содержании, оформлении и порядке представления ТЭО кондиций на минеральное сырье. ГКЗ СССР. М., 1983.

Институт экономики

Академии наук Эстонской ССР
Поступила в редакцию 3/III 1989 


\section{TOOLSE LEIUKOHA FOSFORIIDI KONDITSIOONILISUSEST}

Toolse leiukoha fosforiit on keemilise koostise poolest väga suurtes piirides muutuv, samal ajal aga antakse tooraine konditsioon keskmiste parameetrite alusel arvéstuslikus plokis. Tekib küsimus, kui suur osa toorainest on reaalsetes tootmistingimustes konditsiooniline. Nagu näitab Toolse leiukoha puuraukudest võetud proovide keemilise kóostise statistiline analüüs, pole konditsioonile vastav kuni pool selle leiukoha varudest. Seoses sellega tuleb ümber hinnata kogu bilansiliste varude suurus.

\section{R. PÄSOK, K. TENNO}

\section{ON THE CONDITIONALITY OF THE PHOSPHORITE OF THE TOOLSE DEPOSIT}

The chemical composition of the phosphorites of the Toolse deposit varies greatly. As the conditions set to the raw material are presented on the basis of average parameters in the accounting block, the question arises how much of the raw material meets these conditions in case of real production. As statistical analyses of the chemical composition of the samples taken at the Toolse deposit show, about a half of the reserves do not meet the conditions. Therefore, it is necessary to recalculate the amount of all the recoverable reserves. 